\title{
Acid Phosphatase Enzyme Activity in Mouse Kidney Studied by X-Ray Microanalysis
}

\author{
MERLENE M. BERNAL
}

Department of Chemistry, Rizal Technological University, Mandaluyong City, Philippines Igkon@Yahoo.Com

Lysosomes are membrane-limited vesicles that contain a large number of hydrolytic enzymes the function of which is intracytoplasmic digestion. Lysosomes are most abundant in cells actively undergoing phagocytic activity.

Acid phosphatase (AcP) is one of the hydrolases contained in the lysosome and has been characterized as a marker enzyme for this organelle. In rat kidney, acid phosphatase (AcP) has been localized in Type II and Type IV cytoplasmic bodies of the proximal tubule cells.

The use of acid phosphatase (AcP) as a marker for cell death and/or cell undergoing lysis has been established. Hence, the present study was undertaken to determine possible correlation between the enzyme activity and the maturational development of the animal.

The study used ddY strain mice; ages 1 day, 1 and 2 weeks, and 1, 2, 10 months. For the AcP cytochemistry, the Lanthanide-based method for the ultrastructural localization of AcP was employed [1].

The results of the study showed that the fine localization of AcP was demonstrated in the proximal tubule cells, particularly of the second segment of the mouse kidney (Figs. 1 and 2). Dense reaction deposit as a result of AcP activity with cerium was observed in the lysosome. The lysosomal enzyme reaction deposit appeared homogeneous. However, in other cells it appeared heterogeneous. Likewise, the staining density showed variation in different ages of the animals studied.

In kidney tissue sections incubated with cytochemical AcP medium, using cerium as a capture agent, a dense reaction precipitate as a result of AcP activity was demonstrated in the lysosomes. In the product, the presence of cerium was confirmed qualitatively by X-ray microanalysis [2]. In the recorded spectra (Fig. 4), peak label $\mathrm{La}=4.84 \mathrm{KeV}$ and $\mathrm{Lb}=5.26$ $\mathrm{KeV}$ from element cerium was recorded. Likewise, iron $(\mathrm{Fe})$ and calcium $(\mathrm{Ca})$ were also identified, suggestive of their presence in the lysosome.

The main spectral line of cerium at $\mathrm{La}=4.84 \mathrm{KeV}$ was used in the quantitative computation of the peak-to-background (P/B) ratio. The computed average peak-to-background ratio of the different ages of the animals studied is presented in Fig. 3. As shown, AcP activity decreased significantly from 1 week after birth and progressively until the $10^{\text {th }}$ month. A significant difference of $\mathrm{p}<0.05$ was computed.

References

[1] Olea, M. Acta. Histochem. Cytochem. 24 (1991) 201.

[2] Olea, M. T. and Nagata, T. Cell. Mol. Biol. 37 (1991) 155. 


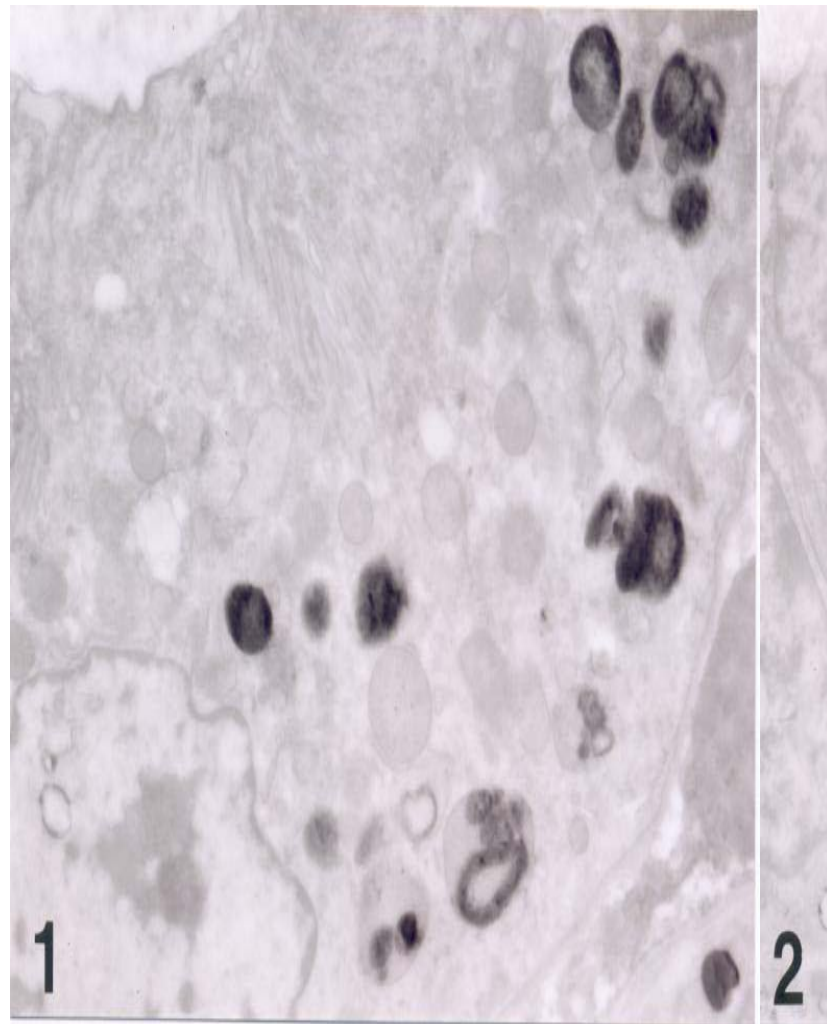

Fig. 1 Electron micrograph of a proximal tubule cell of a two-week-old mouse. Several lysosomes with dense deposit are shown demonstrating AcP activity. Unstained section. Fig. 2 Electron micrograph of a proximal tubule of a day old animal. Unstained section.
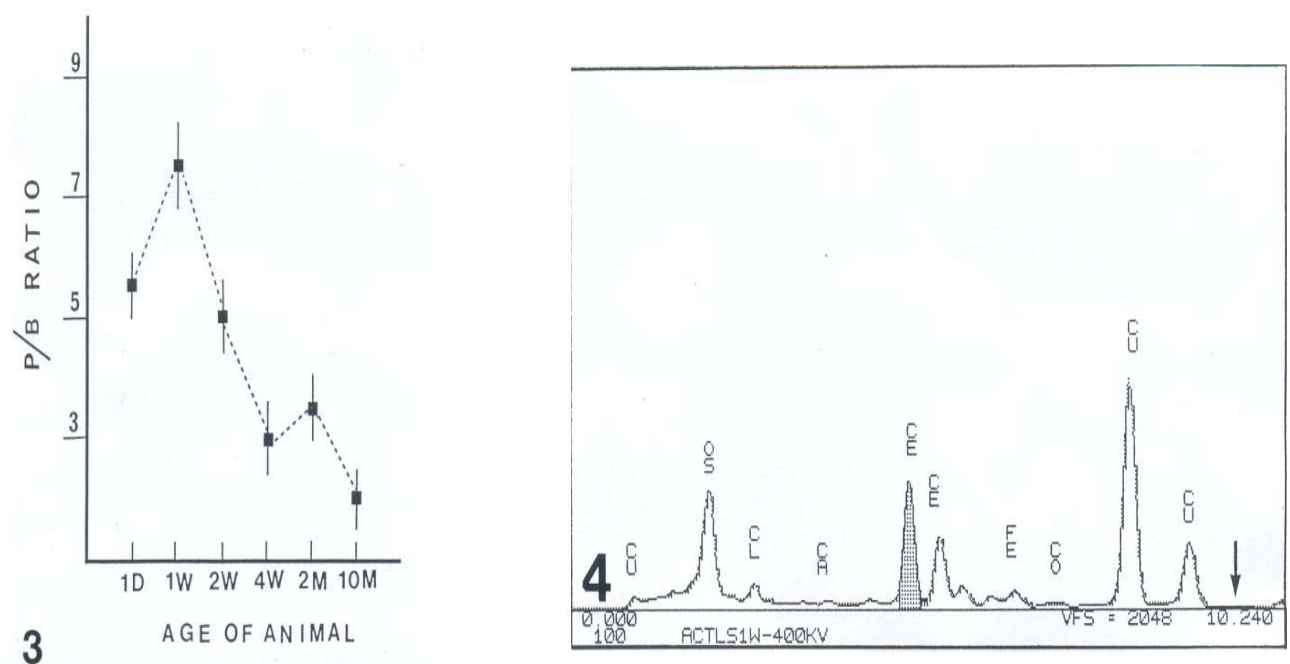

Fig.3 The transitional curve between AcP activity and the maturational development of the different ages of the animal.

Fig.4 X-ray emission line spectrum from lysosome deposit as a result of AcP activity in one-week-old animal. 